\title{
Mutation analysis of the DCX gene and genotype/ phenotype correlation in subcortical band heterotopia
}

\author{
Naomichi Matsumoto ${ }^{1,6}$, Richard J Leventer ${ }^{1,2}$, Julie A Kuc ${ }^{1}$, Stephanie K Mewborn ${ }^{1}$, \\ Laura L Dudlicek ${ }^{1}$, Melissa B Ramocki ${ }^{1}$, Daniela T Pilz ${ }^{4}$, Patti L Mills ${ }^{1}$, Soma Das ${ }^{1}$, \\ M Elizabeth Ross ${ }^{5}$, David H Ledbetter $^{1}$ and William B Dobyns ${ }^{1,2,3}$
}

Departments of ${ }^{1}$ Human Genetics, ${ }^{2}$ Neurology and ${ }^{3}$ Pediatrics, University of Chicago, Chicago, IL, USA; ${ }^{4}$ Institute for Medical Genetics, University Hospital of Wales, Cardiff, UK; ${ }^{5}$ D epartment of Neurology, University of Minnesota, Minneapolis, MN, USA; ${ }^{6}$ D epartment of Human Genetics, Nagasaki School of Medicine, Nagasaki, Japan

Subcortical band heterotopia (SBH) comprises part of a spectrum of phenotypes associated with classical lissencephaly (LIS). LIS and SBH are caused by alterations in at least two genes: LIS1 (PAFAH1B1) at 17p13.3 and DCX (doublecortin) at Xq22.3-q23. DCX mutations predominantly cause LIS in hemizygous males and SBH in heterozygous females, and we have evaluated several families with LIS male and SBH female siblings. In this study, we performed detailed DCX mutation analysis and genotype-phenotype correlation in a large cohort with typical SBH. We screened 26 sporadic SBH females and 11 LIS/ SBH families for DCX mutations by direct sequencing. We found 29 mutations in 22 sporadic patients and 11 pedigrees, including five deletions, four nonsense mutations, 19 missense mutations and one splice donor site mutation. The DCX mutation prevalence was $84.6 \%$ (22 of 26) in sporadic SBH patients and $100 \%$ (11 of 11) in SBH pedigrees. Maternal germline mosaicism was found in one family. Significant differences in genotype were found in relation to band thickness and familial vs sporadic status. European Journal of Human Genetics (2001) 9, 5-12.

Keywords: subcortical band heterotopia; DCX; XLIS; mutation; X inactivation

\section{Introduction}

Typical subcortical band heterotopia (SBH) consists of bilateral and symmetric layers of gray matter interposed between the cerebral cortex and lateral ventricular walls and is the mildest known expression of lissencephaly. Together, lissencephaly (LIS) and SBH comprise a spectrum of malformations associated with deficient neuronal migration ${ }^{1}$ and represent perhaps the best known of a large group of malformations of cortical development.

LIS and SBH are caused by alterations in at least two genes: LIS1 (also known as PAFAH1B1) in $17 \mathrm{p} 13.3^{2,3}$ and DCX (also

Correspondence: William B Dobyns MD, Department of Human Genetics, The University of Chicago, 5841 South Maryland Avenue, Room L041, MC 2050; Chicago, IL 60637, USA. Tel: +1773 834 0555; Fax: +1773 834 0556; E-mail: wbd@genetics.uchicago.edu Current address: Department of Human Genetics, Nagasaki University School of Medicine, Nagasaki, Japan

Received 25 April 2000; revised 26 June 2000; accepted 30 June 2000 known as doublecortin or XLIS) in Xq22.3-q23.,4 Both proteins are known to be microtubule-associated proteins and necessary for correct neuronal migration. ${ }^{6-10}$ Mutations of DCX have been detected in males with isolated lissencephaly sequence (ILS), ${ }^{11}$ and in females with $\mathrm{SBH} .{ }^{4,12-15}$ although rare examples of males with $\mathrm{SBH}^{16}$ and females with lissencephaly ${ }^{17}$ have been reported.

More than 10 families have been reported in which the mothers and affected daughters have SBH, and affected sons have ILSX. ${ }^{1,4,13,15,16}$ LIS and SBH are usually more severe anteriorly in patients with DCX mutations, although in the most severe malformations this may not be evident. This has been described as an anterior greater than posterior $(A>P)$ gradient, which differs from the $P>A$ gradient seen in LIS patients with LIS1 deletions or mutations. ${ }^{11,18}$ Patients with ILS with an A > P gradient associated with DCX mutations may be designated as ILSX to differentiate them from other 
causes of ILS, such as mutations of LIS1. One patient with posterior SBH has been found to have a LIS1 mutation. ${ }^{11}$

Mutation analysis of DCX has been reported by our group and others in sporadic patients with LIS or SBH, with mutation detection frequencies of $12 \%$ in $\mathrm{ILS}^{11}$ and $38 \%$ to $90 \%$ in $\mathrm{SBH} .{ }^{12,13,19}$ The large difference between the studies probably results from phenotypic heterogeneity and different inclusion criteria. In this study, we performed comprehensive mutation analysis of DCX in a large series of sporadic SBH females and ILSX/SBH families by direct PCR sequencing. Our goals were to identify critical functional regions of the DCX protein, the frequency of mutation detection in patients with $\mathrm{SBH}$, and to identify patients with somatic or gonadal mosaicism.

\section{Materials and methods Patients and phenotypic analysis}

As part of our ongoing lissencephaly and cortical malformation research project, we have ascertained 46 patients with SBH including 20 individuals from 11 multiplex families and 26 patients with sporadic diffuse or frontal SBH. Protocols were approved by the appropriate Institutional Review Board Human Subjects Committee. Medical records and cranial MRI scans (or rarely CT scans) were obtained on all probands and all but two carrier mothers. Brain-imaging studies were reviewed with attention to the location and thickness of the band.

Diffuse and frontal predominant bands have been observed primarily in females with mutations of DCX. These were selected as our primary study group comprised of 26 females with sporadic SBH, and 15 females and one male with familial SBH. Some of these families included boys with ILSX. Patients were divided into three subgroups, from most to least common: diffuse thick bands, diffuse thin bands, and frontal predominant thin bands. Representative scans are shown in Figure 1. We included four women who were known or obligatory carriers of DCX mutations in whom an MRI scan was normal or not done. Familial patients came from 11 unrelated multiplex families. Mutations in four of the sporadic SBH patients and six of the multiplex families have been reported previously (Table 1$).{ }^{13,15,16}$

\section{DCX mutation analysis}

DNA was extracted from peripheral blood using a Puregene DNA isolation kit (Gentra system, Minneapolis, MN, USA) according to the manufacturer's protocol. Six DCX exons covering the coding region (exons 4-9) ${ }^{5}$ were amplified by PCR. PCR was cycled 35 times at $95^{\circ} \mathrm{C}$ for $30 \mathrm{~s}, 50^{\circ} \mathrm{C}$ for $30 \mathrm{~s}$, $72^{\circ} \mathrm{C}$ for $1 \mathrm{~min}$ in a volume of $50 \mu \mathrm{l}$, containing $1 \times \mathrm{PCR}$ buffer with $1.5 \mathrm{~mm} \mathrm{MgCl}_{2}, 0.2 \mathrm{~mm}$ each dNTP, $1 \mu \mathrm{M}$ each primer and $2.5 \mathrm{U}$ TaqGold polymerase (PE Applied Biosystems Inc., Foster, CA, USA). Primer sequences have been described previously. ${ }^{11}$ PCR products were purified using the QIAquick PCR purification kit (Qiagen, Chatsworth, CA, USA) and sequenced on both strands with BigDye Terminator chemistry by a standard protocol (PE Applied Biosystems) as described previously. ${ }^{11}$

\section{Southern analysis}

Aliquots of $8 \mu \mathrm{g}$ of genomic DNA were digested with restriction enzymes, Pstl, EcoRI, and HindIII, and separated on a $1 \%$ agarose gel. The DCX CDNA clone was prepared by PCR using the primers, DCX-CD-F (5'-GTC TCT GAG GTT CCA CCA AA-3') and DCX-9R (5'-GGC TTG GAT TTG TAC TCT GGA-3') and Marathon-Ready ${ }^{\mathrm{TM}}$ fetal brain CDNA (Clontech, Palo Alto, CA, USA) as a template. The PCR product was cloned into the pGEM-T vector (Promega, Madison, WI, USA). The cDNA was digested with EcoRI and the insert was used as a probe. Southern transfer, radiolabeling of the probe,
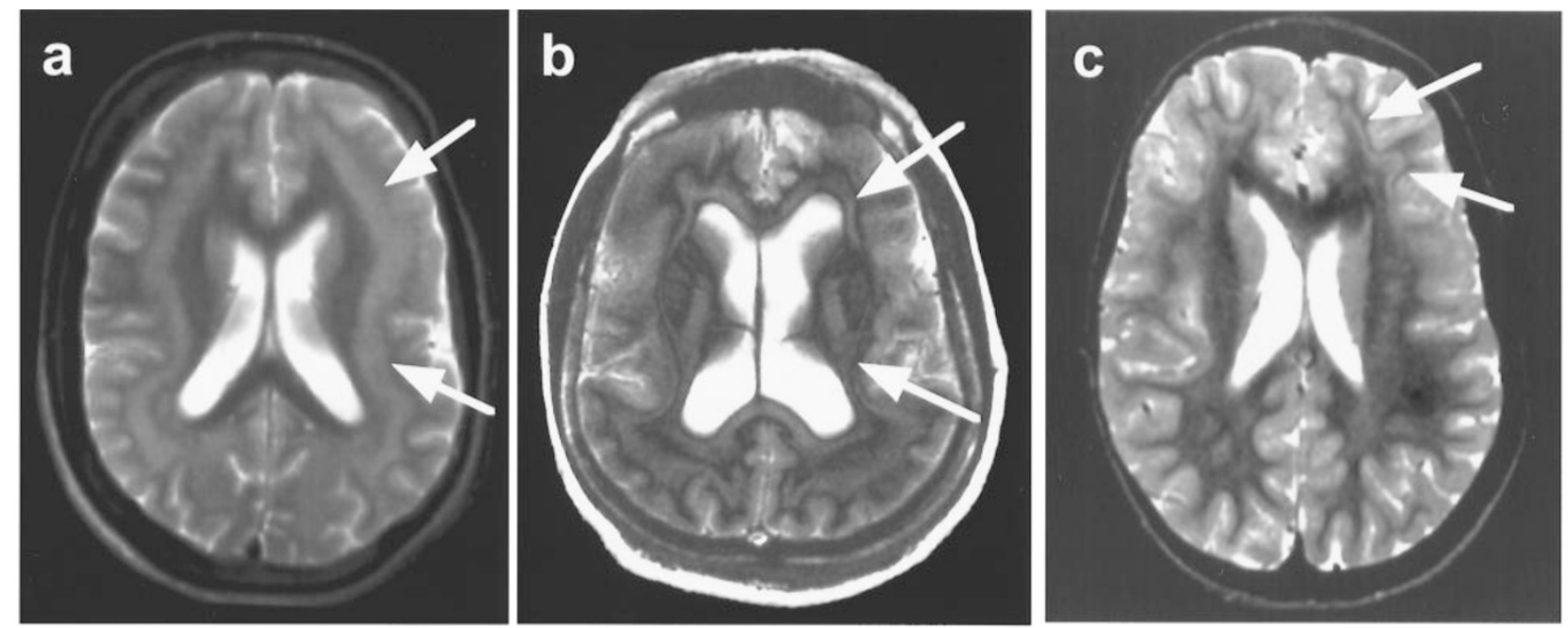

Figure 1 Representative MRI scans in patients with diffuse thick a diffuse thin b and partial frontal thin c SBH. 
Table 1 Results of DCX mutation analysis including mosaicism, and X inactivation status

\begin{tabular}{|c|c|c|c|c|c|}
\hline Subject & Exon & Mutation & $\begin{array}{l}\text { Protein } \\
\text { change }\end{array}$ & $\begin{array}{l}\mathrm{X} \text { inactivation \% } \\
\text { and mosaicism }\end{array}$ & SBH type \\
\hline $\begin{array}{l}\text { Sporadic SBH } \\
\text { LP98-007 } \\
\text { LP99-047 } \\
\text { LP94-055 } \\
\text { LP87-016 } \\
\text { LP99-008 } \\
\text { LP98-047 } \\
\text { LP95-047 } \\
\text { LP96-034 } \\
\text { LP99-034 } \\
\text { LP97-127 } \\
\text { LP99-015 } \\
\text { LP94-057 } \\
\text { LP99-202 } \\
\text { LP97-129 } \\
\text { LP97-055 } \\
\text { LP94-049 } \\
\text { LP98-025 } \\
\text { LP98-026 } \\
\text { LP91-062 } \\
\text { LP93-049 } \\
\text { LP99-201 } \\
\text { LP92-075 }\end{array}$ & $\begin{array}{l}4 \\
4 \\
4 \\
4 \\
4 \\
5 \\
5 \\
5 \\
5 \\
5 \\
5 \\
5 \\
5 \\
5 \\
5 \\
5 \\
5 \\
6 \\
7 \\
7 \\
7 \\
9\end{array}$ & $\begin{array}{l}87-100 \text { del } \\
176 G>A^{a} \\
233 G>T \\
290 T>G \\
311 T>C \\
469 A>T \\
556 C>T^{a} \\
556 C>T^{a} \\
556 C>T^{a} \\
572 C>G \\
599 A>T \\
600 C>G \\
607 A>G \\
641 T>C^{a} \\
646 G>T \\
668 G>T \\
705+2 T>G \\
740-741 \text { del } \\
814 C>T^{a} \\
907 C>T \\
907 C>T \\
(1027-8)-1043 \text { del } 25 \text { bp }\end{array}$ & $\begin{array}{l}\text { Truncation } \\
\text { R59H } \\
\text { R78L } \\
\text { L97R } \\
\text { I104T } \\
\text { K157X } \\
\text { R186C } \\
\text { R186C } \\
\text { R186C } \\
\text { P191V } \\
\text { N200I } \\
\text { N200K } \\
\text { T203A } \\
\text { I214T } \\
\text { E216X } \\
\text { G223V } \\
\text { Truncation } \\
\text { Truncation } \\
\text { R272X } \\
\text { R303X } \\
\text { R303X } \\
\text { Truncation }\end{array}$ & $\begin{array}{l}56 \\
65 \\
\text { NT } \\
\text { NT } \\
53 \\
90 \\
51 \\
\text { NT } \\
56 \\
\text { NT } \\
65 \\
\text { NT } \\
\text { NT } \\
66 \\
78 \\
\text { NT } \\
59 \\
\text { NT } \\
65 \\
\text { NT } \\
\text { NT } \\
86\end{array}$ & $\begin{array}{l}\text { Thick } \\
\text { Thick } \\
\text { Thick } \\
\text { Thin } \\
\text { Thick } \\
\text { Thick } \\
\text { Thick } \\
\text { Thick } \\
\\
\text { Thin } \\
\text { Thick } \\
\\
\text { Thick } \\
\text { Thick } \\
\text { Thick } \\
\text { Thick }\end{array}$ \\
\hline $\begin{array}{l}\text { Familial SBH } \\
\text { LP95-136a2 }^{\mathrm{G}} \\
\text { LP97-034a2 }^{\mathrm{G}} \\
\text { LP98-060a1 }^{\mathrm{P}} \\
\text { LP98-060a2 }^{\mathrm{P}} \\
\text { LP96-031a1 }^{\mathrm{G}, \mathrm{S}} \\
\text { LP96-031a3 }^{\mathrm{G} S \mathrm{~S}} \\
\text { LP95-080a1 }^{\mathrm{G}} \\
\text { LP95-080a2 }^{\mathrm{G}} \\
\text { LP95-080a4 }^{\mathrm{G}} \\
\text { LP97-036a2 }^{\mathrm{G}} \\
\text { LP98-050a2 }^{\text {LP95-084a1 }} \\
\text { LP95-084a2 } \\
\text { LP98-049a2 } \\
\text { LP97-130a1 } \\
\text { LP97-130a2 }\end{array}$ & $\begin{array}{l}4 \\
4 \\
4 \\
4 \\
4 \\
4 \\
5 \\
5 \\
5 \\
5 \\
6 \\
6 \\
6 \\
7 \\
9 \\
9\end{array}$ & $\begin{array}{l}139 A>C \\
256 G>C \\
265 C>G \\
265 C>G \\
299 G>C \\
299 G>C \\
574 C>T \\
574 C>T \\
574 C>T \\
608 C>G \\
\text { exon 6-9 del } \\
751 G>T \\
751 G>T \\
814 C>T^{a} \\
1027 \text { delG } \\
1027 \text { delG }\end{array}$ & $\begin{array}{l}\text { S47R } \\
\text { D86H } \\
\text { R89G } \\
\text { R89G } \\
\text { G100A } \\
\text { G100A } \\
\text { R192W } \\
\text { R192W } \\
\text { R192W } \\
\text { T203R } \\
\text { Truncation } \\
\text { A251S } \\
\text { A251S } \\
\text { R272X } \\
\text { Truncation } \\
\text { Truncation }\end{array}$ & $\begin{array}{l}\text { NT } \\
\text { NT } \\
\text { male } \\
51 \\
\text { NT } \\
\text { NT } \\
77 \\
50 \\
74 \\
\text { NT } \\
72 \\
53 \\
\text { NT } \\
58 \\
72 \\
53\end{array}$ & $\begin{array}{l}\text { Frontal } \\
\text { Frontal } \\
\text { Frontal } \\
\text { Frontal } \\
\text { Frontal } \\
\text { Thin } \\
? \\
\text { Thick } \\
\text { Thick } \\
\text { Thin } \\
\text { Thin }\end{array}$ \\
\hline $\begin{array}{l}\text { Normal or unknow } \\
\text { LP97-140m } \\
\text { LP97-140gm } \\
\text { LP98-050m } \\
\text { LP98-049m }\end{array}$ & $\begin{array}{l}5 \\
5 \\
6-9 \\
7\end{array}$ & $\begin{array}{l}587 G>A \\
587 G>A \\
\text { not detected } \\
\text { not available }\end{array}$ & $\begin{array}{l}\text { R196H } \\
\text { R196H }\end{array}$ & $\begin{array}{l}64 \\
81 \\
\text { gonadal mosaic }\end{array}$ & $\begin{array}{l}\text { Normal MRI } \\
\text { No MRI } \\
\text { No MR } \\
\text { No MRl }\end{array}$ \\
\hline
\end{tabular}

Subject, Lissencephaly Research Project database numbers of all patients with carrier mothers in bold; Superscripts G, S, and $P$ identify patients previously described by Gleeson et al, ${ }^{13}$ Sossey-Alaoui et a ${ }^{15}$ and Pilz et al; ${ }^{16}$ anot novel; NT: not tested; Thick: diffuse thick bands (severe); Thin: diffuse thin bands (moderate); Frontal: frontal thin bands (mild) on brain imaging. The mutation, 265C>G (R89G) in LP98-060a1 and LP98-060a2 was previously described as $264 C>G$. ${ }^{16}$ One mother (LP97-140m) who had three sons with lissencephaly had a germline DCX mutation despite having a normal brain MRI, as she inherited the mutation from the maternal grandmother (LP97-140gm). One mother (LP98050m) who had a son with lissencephaly and a daughter with SBH had gonadal mosaicism for a large deletion of exons 6-9, as the mutation was found in both children, but was not detected by sequencing or Southern blot in the mother.

hybridization to Southern blots with preassociation with human placental DNA and washes were performed as described previously. ${ }^{20}$ An optical scanner (Storm 860, M olecular Dynamics, Sunnyvale, CA, USA) was used to image the blot and the software ImageQuant (Molecular Dynamics) was used for densitometric analysis.

\section{$X$ chromosome inactivation study}

DNA from patients with DCX mutations and 43 normal female controls was used for $X$ chromosome inactivation studies. The androgen receptor (AR)-specific H pall/PCR assay was performed as described elsewhere, in order to assess $X$ inactivation patterns. ${ }^{21,22}$ Genomic DNA ( $\left.1 \mu \mathrm{g}\right)$ was digested 
Table 2 Type and location of mutations in sporadic SBH and familial ILSX/SBH

\begin{tabular}{|c|c|c|c|c|c|c|}
\hline & \multirow[b]{2}{*}{$\mathrm{N}$} & \multicolumn{3}{|c|}{ Exons 4-6 } & \multicolumn{2}{|c|}{ Exons 7-9 } \\
\hline & & $\begin{array}{l}\text { Nonsense or } \\
\text { truncation mutations }\end{array}$ & Missense mutations & $\begin{array}{l}\text { Mosaic mutation } \\
\text { exon 6-9 del }\end{array}$ & $\begin{array}{l}\text { Nonsense or } \\
\text { truncation mutations }\end{array}$ & Missense mutations \\
\hline \multicolumn{7}{|l|}{ LRP } \\
\hline Sporadic SBH & 19 & 5 & 11 & 0 & 3 & 0 \\
\hline Familial ILSX/SBH & 11 & 0 & 8 & $1^{a}$ & 2 & 0 \\
\hline \multicolumn{7}{|l|}{ All reports } \\
\hline Familial ILSX/SBH & 17 & 0 & 13 & $1^{a}$ & 3 & 0 \\
\hline
\end{tabular}

LRP, the Lissencephaly Research Project based at The University of Chicago.

amosaic in the mother (LP98-050m) with no MRJ available, but germline in her daughter (LP98-050a2).

overnight with Hpall and a mock sample without Hpall enzyme was prepared in parallel as a control. PCR amplification was performed with $100 \mathrm{ng}$ of DNA with/without $\mathrm{Hpall}$ digestion and $1 \times$ PCR buffer (Perkin-Elmer), $2.5 \mathrm{~mm} \mathrm{MgCl}_{2}$, $0.2 \mathrm{~mm}$ each dNTP, $0.5 \mathrm{U}$ AmpliTaq Gold (Perkin-Elmer) and primers, AR-1 (5'-TCC AGA ATC TGT TCC AGA GCG TGC-3') and AR-2 (5'-GCT GTG AAG GTT GCT GTT CCT CAT-3'). Three pmol of $\left[{ }^{32} \mathrm{P}\right]$ end-labeled AR-2 primer, 7 pmol of unlabeled AR-2 and 10 pmol of unlabeled AR-1 were used in a $50 \mu$ l PCR reaction. PCR was cycled 30 times at $95^{\circ} \mathrm{C}$ for 45 s, $60^{\circ} \mathrm{C}$ for $30 \mathrm{~s}, 72^{\circ} \mathrm{C}$ for $30 \mathrm{~s}$. Four $\mu$ l of PCR product were electrophoresed in a $4 \%$ polyacrylamide gel with $7 \mathrm{~m}$ urea. A Storm 860 was used to image the dried gel, and densitometric analysis was performed with I mageQuant software. M easurements of each band were obtained in counts per minute (cpm). The percentage of inactivation was calculated as [H pall digested allele $A(d A) /$ undigested allele $A(u A)] /[d A / u A$ + Hpall digested allele $B(\mathrm{~dB}) /$ undigested allele $B(\mathrm{uB})] \times$ 100. $X$ inactivation patterns were classified as random (ratio 50:50 < 75:25) or skewed (ratio >75:25). The chi-square test was performed for statistical analysis.

\section{Results}

\section{DCX mutation analysis in SBH females}

We amplified DCX exons 4-9 from DNA of 26 sporadic SBH patients, and 20 members of 11 multiplex families with SBH, or both SBH and ILSX. Mutation analysis was performed by direct sequencing of both strands. We found nucleotide changes in 22 of the 26 sporadic SBH females, and 10 of 11 families. The remaining multiplex family had a large del etion detected by Southern analysis. All changes are predicted to be causative mutations, and are summarized in Tables 1 and 2, and Figure 2. Nucleotide and amino acid numbering are according to the doublecortin mRNA sequence (GenBank accession no. AF034634). ${ }^{5}$ Thus, the prevalence of DCX mutations in our cohort was $84.6 \%$ (22 of 26 ) in sporadic $\mathrm{SBH}$, and $100 \%$ (11 of 11 ) in ILSX/SBH families.

We identified 19 missense mutations (14 novel) including the same 556C > T mutation in three unrelated patients, four nonsense mutations (two novel), four small deletions (three novel) of 1 to $25 \mathrm{bp}$, one large deletion (novel) including exons 6-9, and one splice donor site mutation (novel) in intron 5 which could lead to exon 5 skipping. None of the missense mutations affected the Abl phosphorylation site (aa66-73) in exon 4 or the serine/prolinerich (SPR) region (aa315-341) in exon 8. ${ }^{5}$ Many of these mutations did involve the proposed microtubule binding region in exon 4 (aa1-110), ${ }^{8}$ although this region is not well defined. Two evolutionary conserved domains (aa 51-135 and aa 178-259) ${ }^{10}$ cover the majority of missense mutations. All of the deletions and the splice site mutations were predicted to lead to aberrant proteins. However, we could not prove the predicted splicing error at the mRNA level because DCX is expressed at very low levels in lymphoblastoid cells.

\section{Genotype-phenotype correlation}

The prevalence of nonsense/truncation mutations of exons 4-6 was significantly different in sporadic (16/39) compared to familial $(0 / 17)$ patients $(P<0.005)$. We also found potentially significant differences between patients with different SBH phenotypes (Table 3). Specifically, missense mutations of exons 4-6 were detected in nine of 14 (64\%) patients with diffuse thick SBH, and in seven of seven (100\%) patients with thin frontal SBH or a normal MRI, although chi-square analysis did not reach significance $(0.1>\mathrm{P}>$ 0.05). However, the prevalence of nonsense and truncation mutations was significantly different in the combined diffuse thick plus diffuse thin group (8/19), compared with the combined frontal thin plus normal MRI group $(0 / 7)(P<$ 0.05).

\section{Germline (gonadal) mosaicism}

We found a large deletion involving exons 6 to 9 in one family (LP98-050) in which a son had ILSX and a daughter had SBH (Figure 3). PCR successfully amplified exons 4 and 5 in the boy but failed to amplify exons 6-9 (data not shown). Five restriction fragments (a-e) from Pstl-digested normal control DNA showed hybridization to the DCX CDNA probe by Southern analysis. Three of the five restriction fragments (b, d, e) were missing from Pstl-digested DNA from the boy (Figure 3). The deleted region is expected to be $21 \mathrm{~kb}$ 


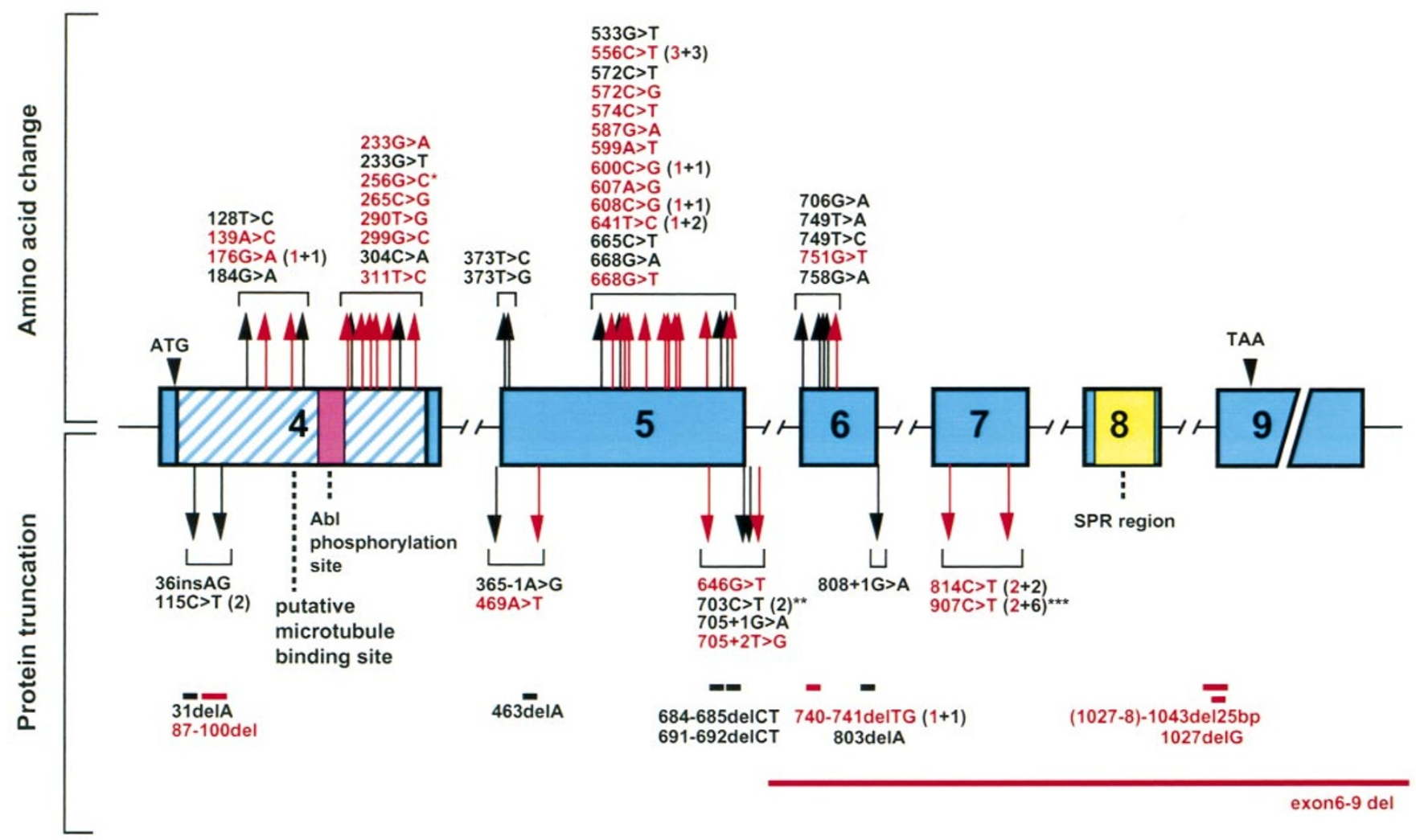

Figure 2 Schematic representation of the DCX gene. The exons are depicted as light-blue boxes, the putative microtubule binding portion is shown as a striped light-blue box, the Abl phosphorylation site is shown as a pink box, and the serine/proline rich region is shown as a yellow box. The missense mutations are indicated above the gene, and the deleted portions of the gene indicated as thick lines and other protein truncation mutations are shown below the gene scheme. The mutations identified in this study are shown in red, published mutations are in black. ${ }^{41-16,19}$ Parenthesis indicates number of cases in this study (red) and number of cases described elsewhere (black). ATG: initiation codon, TAA: stop codon. *the mutation, 265C > G (R89G) in LP98-060a1 and LP98-060a2 was originally described as $264 \mathrm{C}>\mathrm{G}$ previously. ${ }^{16}$ **Patient 13 by Gleeson et al ${ }^{13}$ was originally reported to harbor a nonsense mutation $705 \mathrm{G}>\mathrm{A}$, but this mutation was corrected as 703C > T (personal communication, JG Gleeson, 2000). ****Patient 49 by Gleeson et al ${ }^{13}$ was originally reported to have a nonsense mutation $908 \mathrm{~A}>\mathrm{G}$, but this was also corrected as $907 \mathrm{C}>\mathrm{T}$ (personal communication, JG Gleeson, 2000).

Table 3 Genotype-phenotype correlation in sporadic and familial SBH

\begin{tabular}{|c|c|c|c|c|c|}
\hline \multirow[b]{2}{*}{ Type of SBH } & \multirow[b]{2}{*}{$\mathrm{N}$} & \multicolumn{2}{|c|}{ Exons 4-6 } & \multicolumn{2}{|c|}{ Exons 7-9 } \\
\hline & & $\begin{array}{l}\text { Nonsense or } \\
\text { truncation mutations }\end{array}$ & Missense mutations & $\begin{array}{l}\text { Nonsense or } \\
\text { truncation mutations }\end{array}$ & M issense mutations \\
\hline Diffuse thick & 14 & 2 & 9 & 3 & 0 \\
\hline Diffuse thin & 5 & 1 & 2 & 2 & 0 \\
\hline Frontal thin & 6 & 0 & 6 & 0 & 0 \\
\hline Normal MRI & 1 & 0 & 1 & 0 & 0 \\
\hline
\end{tabular}

according to the sizes of these restriction fragments. Densitometric analysis of Pstl-digested DNA from the daughter showed a $50 \%$ reduction in intensity of the same fragments (b, d, e) but the mother's restriction fragments (b, d, e) showed the same level of intensity observed in normal controls. Restriction enzymes EcoRI and HindlII showed similar results (data not shown).

\section{$X$ chromosome inactivation}

$X$-inactivation studies showed skewing of $>75 \%$ in five SBH patients $(21.7 \%)$ whose mutations included two nonsense mutations (K157X, E216X), two missense mutations (R192W, $\mathrm{R} 196 \mathrm{H})$, and one small deletion [(1027-8)-1043del]. The prevalence of skewing in 43 normal controls was 30.2\% (13 of 43). We did not identify a significant difference in $X$ 

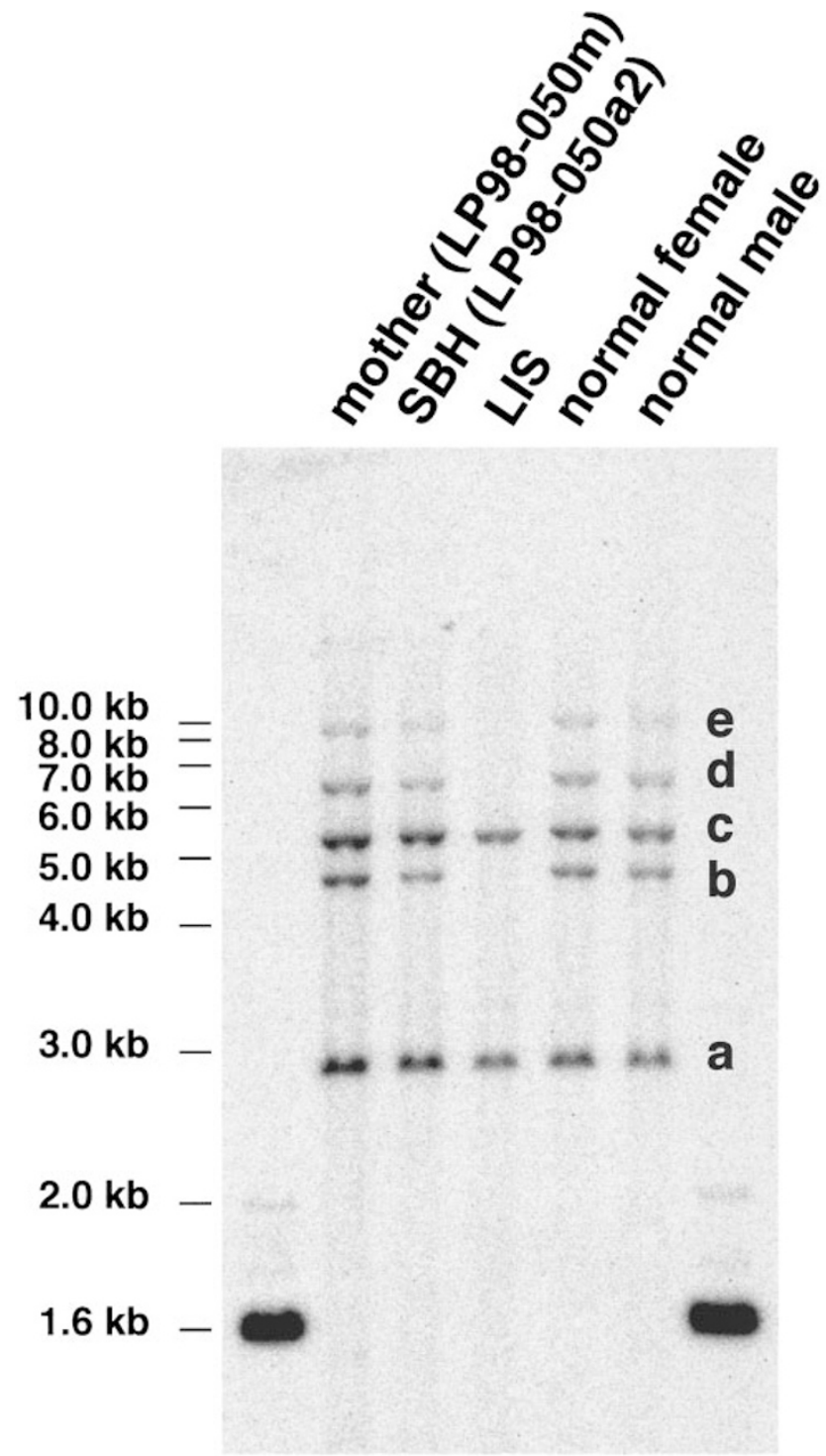

Figure 3 Southern analysis using a DCX CDNA probe on Pst। digested DNAs of the family (LP98-050). Mother: LP98-050m, LIS: the LIS male, SBH: the SBH female (LP98-050a2). Restriction fragments, $b, d$ and e are missing in the LIS male. Fragments $a$ and $c$ were used as controls for densitometric analysis because these fragments were not deleted in the LIS male. DNA intensity ratio $(b+d+e / a+c)$ of SBH, mother, a normal control male, a normal control female is $0.33,0.59,0.61$, and 0.60 , respectively.

inactivation skewing between SBH patients and normal controls. Furthermore, we found several multiplex families in which individuals with similar phenotypes had markedly variable $\mathrm{X}$-inactivation status (Table 1 ).

\section{Discussion}

Discovery of the first two lissencephaly genes, LIS1 and DCX, has allowed rapid progress in our understanding of the

biological basis of neuronal migration. Previous studies have proposed several potentially important functional regions of the DCX protein, including a putative microtubule binding region in exon 4,8 a potential $\mathrm{Abl}$ phosphorylation site also in exon $4,^{5}$ and a serine-proline rich region in exon $8 .^{5}$ Mutation clusters were previously identified in exons 4 and 5 , affecting part of the proposed microtubule binding site, and in exons 5 and $6 .^{7}$ These two clusters significantly overlap with two proposed evolutionarily conserved domains. ${ }^{10}$ The first conserved domain can bind tublin and enhance microtubule polymerization, and the second binds tubulin less and does not enhance microtubule assembly. Both domains seem necessary for optimal doublecortin function and differences in the location and types of mutation in these regions may produce variable functional disturbances. We combined our data and data from all available previous reports in Figure 2 to show 52 known mutations of the DCX gene. One missense mutation, 128T > C (L43S), is outside the two mutation clusters reported by Gleeson et al, ${ }^{19}$ but the remaining known missense mutations occurred within these clusters (nt 139-373 and nt 533-758), which comprise $43 \%$ of the coding region. Similarly, $81 \%$ (17 of 21 ) of all nonsense and protein truncation mutations were also found in exons 4-6. This further supports the functional importance of this region.

We reviewed 52 known DCX mutations and found several hot spots for mutation. ${ }^{4,11-16}$ The missense mutation 556C > $\mathrm{T}$ (R186C) was found in six unrelated patients, while 641T > C (I214T) was detected in three patients. The nonsense mutation 907C > T (R303X) was found in eight patients and $814 C>T(R 272 X)$ in four. All mutations consisted of transitions ( $\mathrm{C}>\mathrm{T}$ or $\mathrm{T}>\mathrm{C}$ ), which are more frequent than transversions. ${ }^{23}$ These four hot spots comprise $26.6 \%$ (21 of 79) of all known patients with DCX mutations. Another three missense mutations including 176G > A (R59H), 600C > G (N200K) and 608C > G (T203R), two nonsense mutations including $115 \mathrm{C}>\mathrm{T}(\mathrm{R} 39 \mathrm{X})$ and $703 \mathrm{C}>\mathrm{T}(\mathrm{Q} 235 \mathrm{X})$, and one 2-bp deletion (740-741delTG) were each found in two unrelated probands. These 10 hot spots comprise $41.8 \%$ (33 of 79) of all patients with mutations.

The frequency of DCX mutation is $84.6 \%$ (22 of 26) in sporadic SBH females and $100 \%$ (11 of 11 ) in ILSX/SBH families in this study. The prevalence of DCX mutations has been reported in two previous studies. In the first, mutations were detected by DGGE in nine of 10 sporadic SBH patients (90\%), but no data regarding the subtype of SBH was provided. ${ }^{12}$ In the largest series, DCX mutations were detected using SSCP in 18 of 47 sporadic SBH patients (38\%). ${ }^{13}$ Repeat analysis of this group by direct PCR sequencing detected only one additional mutation. ${ }^{19}$ Reassessment of these patients using inclusion criteria similar to our study showed mutations in $67 \%$ (16 of 24). ${ }^{19}$ Thus, the consensus frequency of mutations in the most common forms of sporadic SBH (diffuse thick, diffuse thin and partial frontal thin) is about $80 \%$. 
Our clinical experience suggested a milder phenotype in familial compared with sporadic patients and thus we compared mutations between these groups. This comparison of sporadic and familial patients showed significant differences between mutations in exons 4-6 and exons 7-9. Among sporadic patients, missense mutations were detected in exons 4-6, and nonsense or protein truncation mutations throughout the coding region in exons 4-9. Results in familial patients were quite different, showing that abnormalities in exons 4-6 were all missense mutations, except for one family with a large deletion in which the mother had gonadal (or very low level somatic) mosaicism. In contrast, mutations found in exons 7-9 were nonsense mutations or protein truncations. The prevalence of nonsense/truncation mutations of exons 4- 6 was significantly different in sporadic $(16 / 39)$ compared with familial $(0 / 17)$ patients $(P<0.005)$.

The phenotypic spectrum in females with diffuse or partial frontal SBH is wide, varying from severe mental retardation and intractable epilepsy to normal intelligence and mild epilepsy. Clinical severity has been observed to vary with band thickness. ${ }^{24}$ Patients with thin partial frontal bands have the mildest phenotypes and may be asymptomatic. We therefore compared band location and thickness in different types of DCX mutations. Among patients with diffuse thick bands, a full spectrum of mutations were found except for missense mutations in exons 7-9, as noted previously. Among patients with frontal thin bands, all werefamilial and all had missense mutations in exons 4-6. The prevalence of nonsense/truncation mutations was significantly different in the combined diffuse thick plus diffuse thin group (8/19) compared with the combined frontal thin plus normal group $(0 / 7)(P<0.05)$. These results support a correl ation between genotype and band phenotype.

We examined lymphocyteX inactivation status in SBH. We recognize that brain tissue should bestudied, but this was not available. We found no significant skewing of $X$ inactivation in general, and variable $X$ inactivation status within familial SBH with the same mutations. Thus, the contribution of $X$ inactivation to the SBH phenotype may be less than pre viously thought, but these studies need to be repeated on brain tissue of affected patients.

We discovered one carrier mother with gonadal or low level somatic mosaicism and suspected but could not confirm another. One girl (LP98-050a2) with a presumably thick SBH (no brain imaging available for review) and moderate mental retardation had a germline deletion of exons 6-9 detected by densitometric Southern analysis. Her brother had ILSX, implying that her mother must have gonadal or low level somatic mosaicism undetectable by Southern analysis. In another family, the mother (LP98-049 m) was clinically normal, but had a daughter with SBH (LP98-049a2) and severe mental retardation, and a son with ILSX. A nonsense mutation (R272X) was found in both the affected son and daughter. Unfortunately, neither maternal MRI scans nor
DNA was available for study. Gonadal mosaicism in SBH has been reported once previously. ${ }^{13}$

In conclusion, we have shown that the rate of DCX mutations is high in both sporadic and familial typical SBH cases. There appears to be a relationship between the genotype and phenotype, particularly in distinguishing sporadic from familial cases, and diffuse from partial bands. The striking difference in phenotype observed between males with ILSX and females with SBH implies that functional mosaicism due to $X$ inactivation is important in determining the phenotype. Our findings support mutational heterogeneity as an additional important factor in determining phenotype severity and provide further support for the observation that the $3^{\prime}$ end of the protein may contain regions of less functional significance. Somatic mosaicism may be an additional important variable. We were unable to confirm any effects from skewing of $X$ inactivation using lymphocytes, but plan to perform these studies on brain tissue of affected patients when suitable tissue is available.

\section{Acknowledgements}

We would like to thank all the families and clinicians whose co-operation made this study possible. This work was supported in part by grants from the National Institutes of Health to WBD, DHL and MER (P01-NS39404) and to MER and W BD (R01-NS35515), and by the Lissencephaly Network Inc. to The University of Chicago Department of Human Genetics.

\section{References}

1 Dobyns WB, Andermann E, Andermann F et al: X-linked malformations of neuronal migration. Neurology 1996; 47: 331-339.

2 Lo Nigro C, Chong SS, Smith ACM, Dobyns WB, Ledbetter DH: Point mutations and an intragenic deletion in LIS1, the lissencephaly causative gene in isolated lissencephaly sequence and Miller-Dieker syndrome. Hum M ol Genet 1997; 6: 157-164.

3 Reiner O, Carrozzo R, Shen Y et al: Isolation of a Miller-Dieker lissencephaly gene containing $G$ protein beta-subunit-like repeats. Nature 1993; 364: 717-721.

4 des Portes V, Pinard JM, Billuart P et al: A novel CNS gene required for neuronal migration and involved in X-linked subcortical laminar heterotopia and lissencephaly syndrome. Cell 1998; 92: 51-61.

5 Gleeson JG, Allen KM, Fox JW et al: Doublecortin, a brain-specific gene mutated in human $X$-linked lissencephaly and double cortex syndrome, encodes a putative signaling protein. Cell 1998; 92: 63-72.

6 Francis F, Koulakoff A, Boucher D et al: Doublecortin is a developmentally regulated, microtubule-associated protein expressed in migrating and differentiating neurons. Neuron 1999; 23: $247-256$.

7 Gleeson JG, Lin PT, Flanagan LA, Walsh CA: Doublecortin is a microtubule-associated protein and is expressed widely by migrating neurons. Neuron 1999; 23: 257-271.

8 Horesh D, Sapir T, Francis F et al: Doublecortin, a stabilizer of microtubules. Hum Mol Genet 1999; 8: 1599-1610.

9 Sapir T, Elbaum M, Reiner O: Reduction of microtubule catastrophe events by LIS1. EMBO J 1997; 16: 6977-6984.

10 Sapir T, Horesh D, Caspi M et al: Doublecortin mutations cluster in evolutionarily conserved functional domains. Hum Mol Genet 2000; 9: 703-712. 
11 Pilz DT, Matsumoto N, Minnerath S et al: LIS1 and XLIS (DCX) mutations cause most classical lissencephaly, but different patterns of malformation. Hum Mol Genet 1998; 13: 2029-2037.

12 des Portes V, Francis F, Pinard J-M et al: Doublecortin is the major gene causing $X$-linked subcortical band laminar heterotopia (SCLH). Hum Mol Genet 1998; 7: 1063-1070.

13 Gleeson JG, Minnerath SR, Fox JW et al: Characterization of mutations in the gene doublecortin in patients with double cortex syndrome. Ann Neurol 1999; 45: 146-153.

14 Kato $M$, Kimura $T$, Lin $C$ et al: A novel mutation of the doublecortin gene in Japanese patients with $X$-linked lissencephaly and subcortical band heterotopia. Hum Genet 1999; 104: 341-344.

15 Sossey-Alaoui K, Hartung AJ, Guerrini R et al: Human doublecortin (DCX) and the homologous gene in mouse encode a putative $\mathrm{CA}^{2+}$-independent signaling protein which is mutated in human X-linked neuronal migration defects. Hum Mol Genet 1998; 7: 1327-1332.

16 Pilz DT, Kuc JA, Matsumoto $\mathrm{N}$ et al: Subcortical band heterotopia in rare affected males can be caused by missense mutations in DCX (XLIS) or LIS1. Hum Mol Genet 1999; 8: 1757-1760.

17 DobynsWB, EliasER, Newlin AC, Pagon RA, Ledbetter DH: Causal heterogeneity in isolated lissencephaly. Neurology 1992; 42: 1375-1388.
18 Dobyns WB, Truwit CL, Ross ME et al: Differences in the gyral pattern distinguish chromosome 17-linked and X-linked lissence phaly. Neurology 1999; 53: 270-277.

19 Gleeson J, Luo R, Grant P et al: Genetic and neuroradiologic heterogeneity of double cortex syndrome. Ann Neurol 2000; 47: 265-269.

20 Kubota T, Sutcliffe JS, Aradhya Set al: Validation studies of SNRPN methylation as a diagnostic test for Prader-Willi syndrome. Am J Med Genet 1996; 66: 77-80.

21 Allen RC, Zoghbi HY, Moseley AB, Rosenblatt HM, Belmont JW: Methylation of Hpall and Hhal sites near the polymorphic CAG repeat in the human androgen-receptor gene correlates with $X$ chromosome inactivation. Am J Hum Genet 1992; 51: 1229-1239.

22 Monteiro J, Derom C, Vlietinck R, Kohn N, Lesser M, Gregesen P: Commitment to $X$ inactivation precedes the twinning event in monochorionic MZ twins. Am J Hum Genet 1998; 63: 339-346.

23 Collins DW, Jukes TH: Rates of transition and transversion in coding sequences since the human-rodent divergence. Genomics 1994; 20: 386-396.

24 Barkovich AJ, Guerrini R, Battaglia G et al: Band heterotopia: correlation of outcome with magnetic resonance imaging parameters. Ann Neurol 1994; 36: 609-617. 